\title{
PREDATORY CAPTURE OF BOMBARDIER BEETLES BY A TABANID FLY LARVA*
}

\author{
By Stephen Nowicki and Thomas Eisner \\ Section of Neurobiology and Behavior \\ Cornell University, Ithaca, NY 14853
}

While collecting bombardier beetles (Brachinus spp.) on the evening of August 27, 1982, by a pond near Portal, Cochise County, Arizona, a group of us, including Rodger Jackman of the British Broadcasting Corporation and Maria Eisner, came upon an unusual phenomenon. Thousands of young adults of the spadefoot toad, Scaphiopus multiplicatus, were active beside the pond on that night, having just emerged from the water after metamorphosis. On close observation we noted a number of these toads that were dead or dying and in various stages of partial submergence in the mud. Each had been grasped from beneath by a larva of the horsefly Tabanus punctifer, a mud-dwelling predator, which had seized it with its hooked mouthparts, had pulled it partly into the substrate, and was embibing its body fluids. Details of this first known occurrence of predation by a fly larva on an adult amphibian will be published elsewhere. Our purpose here is to call attention to another extraordinary ability of this larva: the capture of bombardier beetles.

We transported several of the larvae to our Cornell laboratories and established them individually in mud-filled enclosures, where they quickly buried themselves, leaving only their mouthparts exposed at the surface (Fig. 1A). We maintained the larvae on young spadefoot toads, which they captured as they had in the field, and also on insects, which judging from published accounts on tabanid larvae (Webb and Wells, 1924; Oldroyd, 1964; Burger, 1977), must be a principal staple of their diet. They proved capable even of capturing large crickets (Teleogryllus oceanicus), which they hooked by a leg, drew partly into the mud, and then held for hours while sucking out their body contents.

\footnotetext{
*Paper No. 73 of the series Defense Mechanisms of Arthropods. Paper No. 72 is T. Eisner and J. Meinwald, Psyche 89, 357-367, 1983.

Manuscript received by' the editor January' 6, 1983
} 

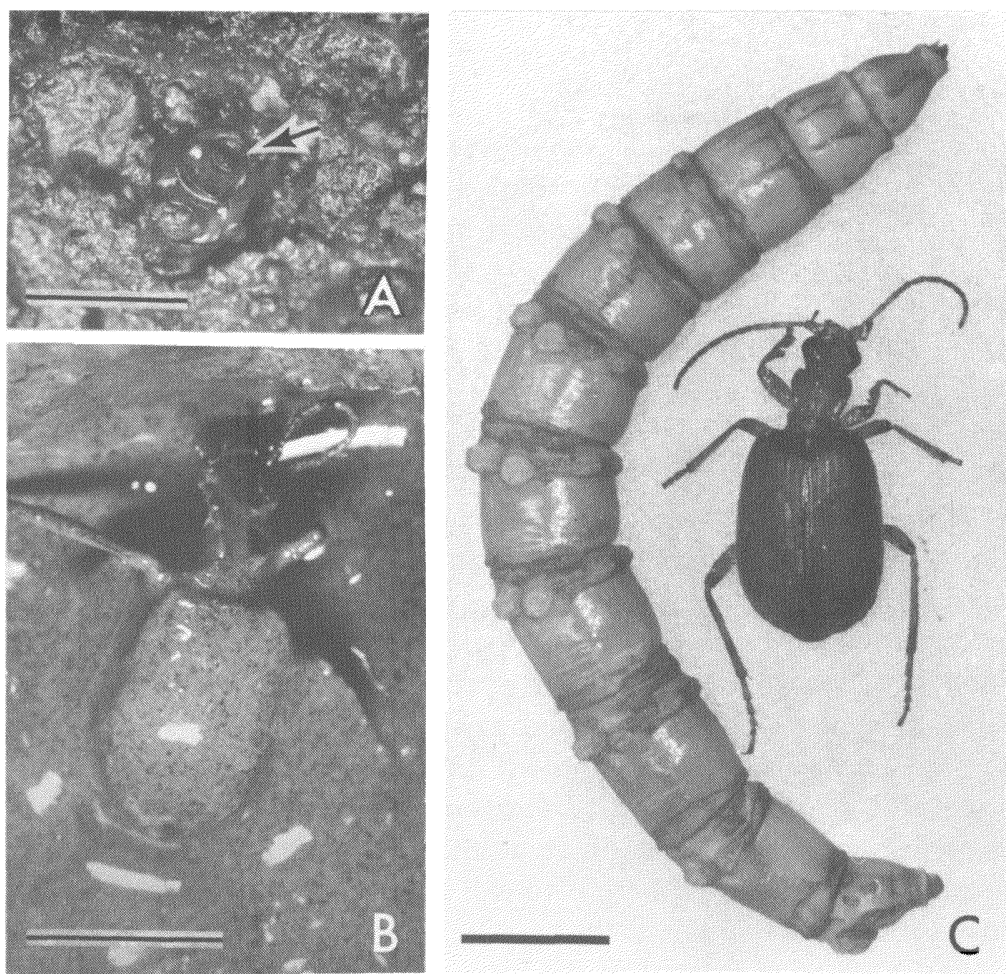

Figure 1. (A) Mouthparts (arrow) of a buried T. punctifer larva, projecting just above the surface of the mud, as the animal lies in wait of prey. (B) Bombardier beetle, caught by a submerged larva and partly drawn into the mud, in the process of being eaten (the larvae can also pull beetles into drier mud than here shown). (C) Full grown $T$. punctifer larva beside an average-sized bombardier beetle. Reference bars $=$ $5 \mathrm{~mm}$.

Bombardier beetles are doubtless among the most invulnerable of insects. The quinone-containing spray that they eject from their abdominal defensive glands when attacked is hot $\left(100^{\circ} \mathrm{C}\right)$ and is aimed accurately toward the predator by rotation of the abdominal tip (Eisner, 1958; Aneshansley et al., 1969). A number of broadly insectivorous predators have been shown to be repelled by the spray, including ants, spiders, preying mantids, and toads (Eisner, 1958; Eisner and Dean, 1976; Dean, 1980).

We staged encounters between bombardier beetles and T. punctifer larvae by releasing the beetles singly onto the mud in the larval 
enclosures. The beetles all stemmed from the larval collecting site, where they were taken at the very places on the edge of the pond where the larvae were also abundant. In three encounters we were fortunate to witness the beginnings of the attack. The events proceeded quickly and were the same in each case. No sooner had a beetle brought one of its tarsi to rest upon the mouthparts of the larva, than it was grasped by that tarsus and caused to spray. There were sometimes several discharges, audible at times and visible as misty puffs, but the larva, which had withdrawn below the surface the moment it hooked on to the beetle's leg, was already out of reach. The beetle struggled as it was gradually pulled into the mud, but the larva never released its hold. Partly submerged, the beetle eventually died (Fig. 1B), and when retrieved next day was found to be largely eaten out. Five additional encounters that were not witnessed from the outset were equally fatal to the beetles. We assume that the death of the beetles was hastened by the salivary toxins that tabanid larvae are said to inject into their insect prey (Schmidt, 1982).

Given the ecological co-occurrence of $T$. punctifer larvae and bombardier beetles, we feel that encounters between the two must inevitably occur also in nature, with the same outcome as in the laboratory. Moreover, the larvae must have access also to diverse other insects that discharge noxious secretions, includings ants, tiger beetles, and additional Carabidae. Species of Chlaenius, for example, whose odor was unmistakably suggestive of the phenolic output that characterizes other beetles of the genus (Eisner et al., 1963), scurried about together with Brachinus at our collecting site at night. Against such chemically protected insects, the predatory tactic of lurking just beneath the surface, and of withdrawing into the mud for total cover the moment a victim is seized and caused to activate its defenses, doubtless serves the larvae well. Other muddwelling tabanid larvae of similar opportunistic feeding habits might equally profit from the tactic.

\section{ACKNOWLEDGEMENTS}

Study supported by Grant AI02908 from NIH; we thank Drs. John F. Burger and Rodolfo Ruibal for helpful information and for identifying the larva and toad respectively, and Maria Eisner for technical help. 


\section{References Cited}

ANeshansley, D. J., T. Eisner, J. M. Widom, AND B. Widom

1969. Biochemistry at $100^{\circ} \mathrm{C}$ : Explosive secretory discharge of bombardier beetles (Brachinus). Science 165:61-63.

BURger, J. F.

1977. The biosystematics of immature Arizona Tabanidae (Diptera). Trans. Amer. Ent. Soc. 103:145-258.

DEAN, J.

1980. Encounters between bombardier beetles and two species of toads (Bufo americanus, B. marinus): Speed of prey-capture does not determine

EISNER, T. prey-capture success. J. Comp. Physiol. 135:41-50.

1958. The protective role of the spray mechanism of the bombardier beetle, Brachynus ballistarius Lec. J. Insect Physiol. 2: 215-220.

EISNER, T. AND J. DEAN

1976. Ploy and counterploy in predator-prey interactions: orb-weaving spiders versus bombardier beetles. Proc. Nat. Acad. Sci. USA 73:1365-1367.

Eisner, T., J. J. Hurst, and J. Meinwald

1963. Defense mechanisms of arthropods. XI. The structure, function, and phenolic secretions of the glands of a chordeumoid millipede and a carabid beetle. Psyche 70:94-116.

OLDROYD, $\mathrm{H}$.

1964. The Natural History of Flies. Norton: New York.

Schmid, J. O.

1982. Biochemistry of insect venoms. Ann. Rev. Entom. 27:339-368.

WeBB, J. L. AND R. W. WeLlS

1924. Horse-flies: Biologies and relation to western agriculture. U. S. Dept. Agr. Bull. 1218. 

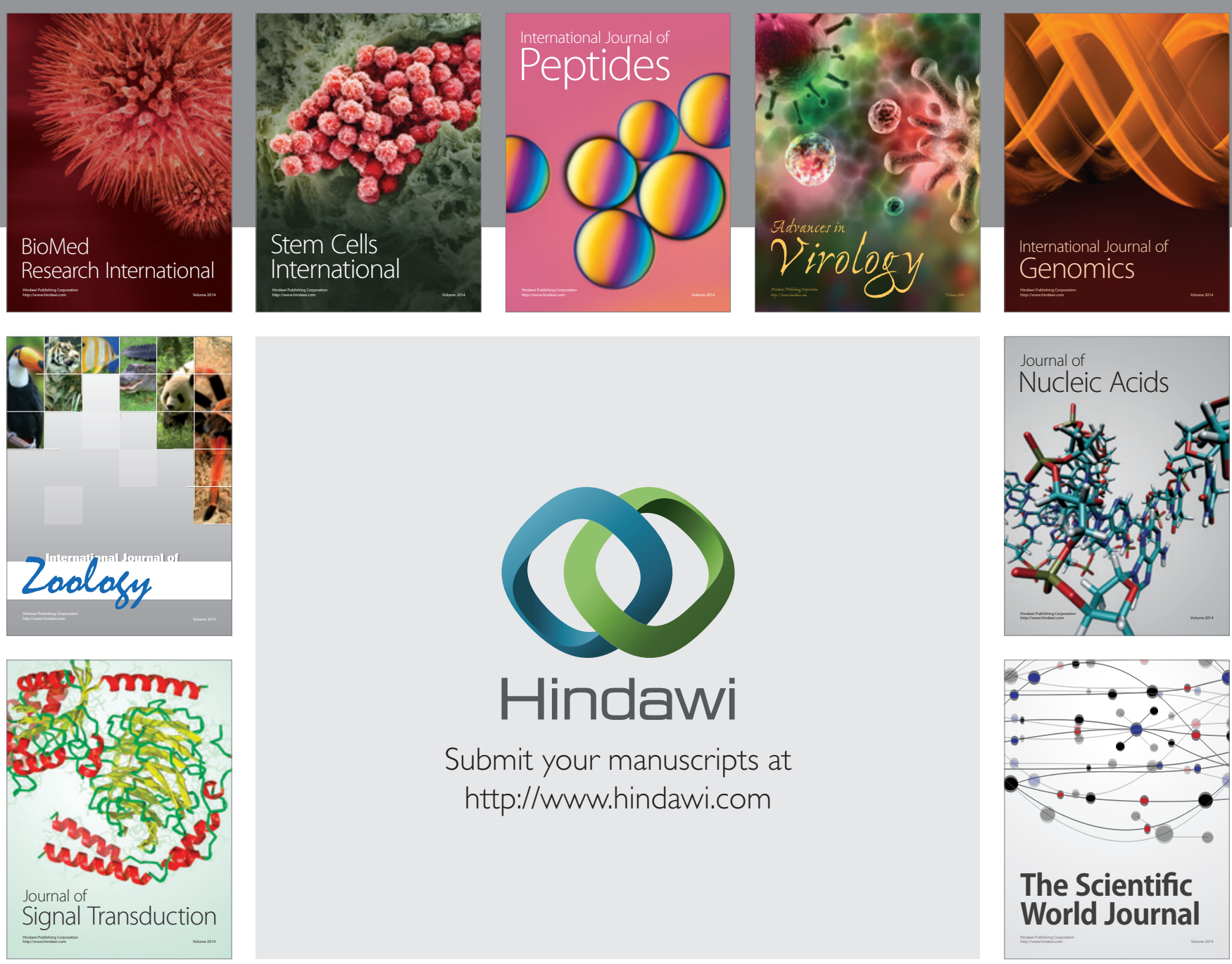

Submit your manuscripts at

http://www.hindawi.com
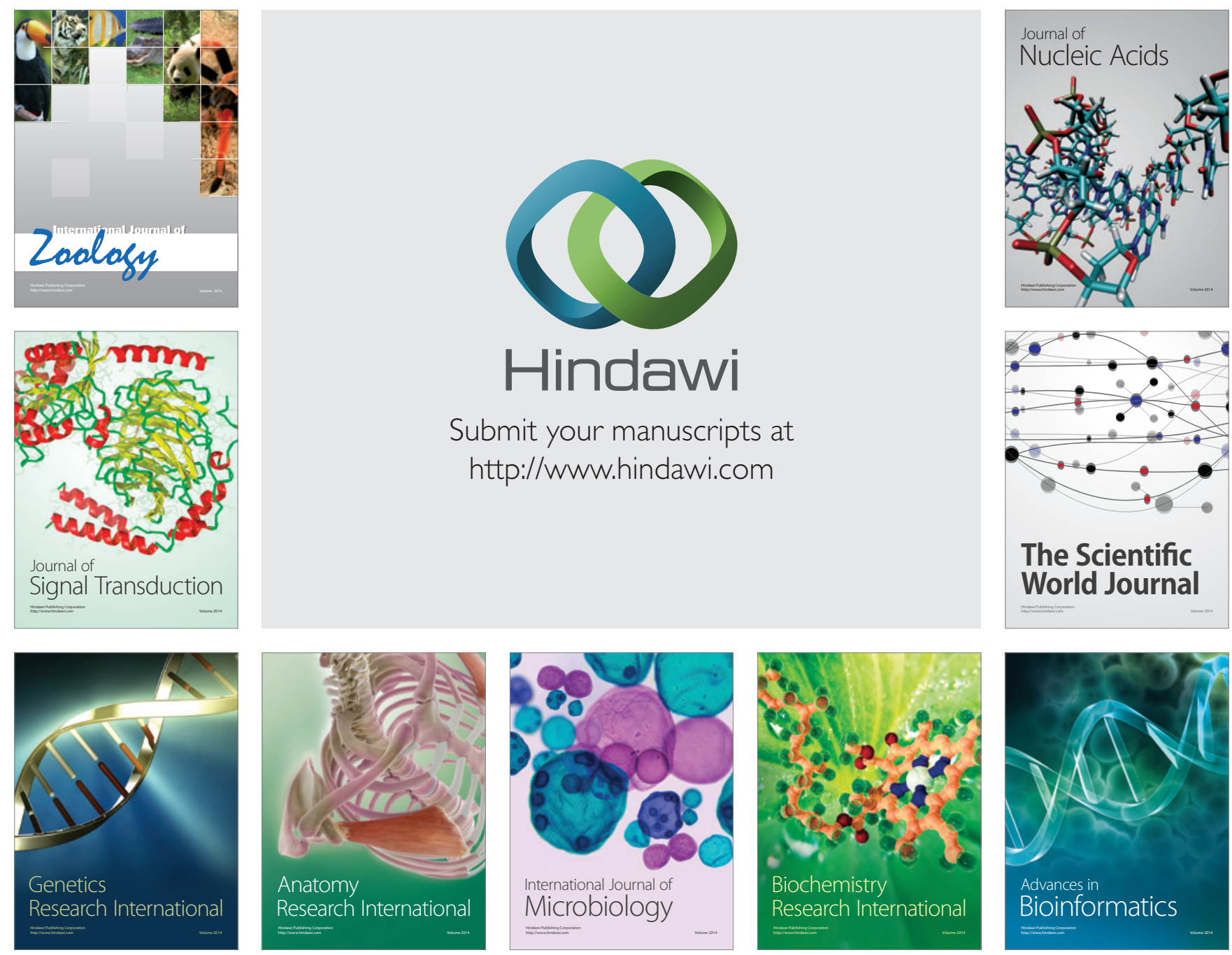

The Scientific World Journal
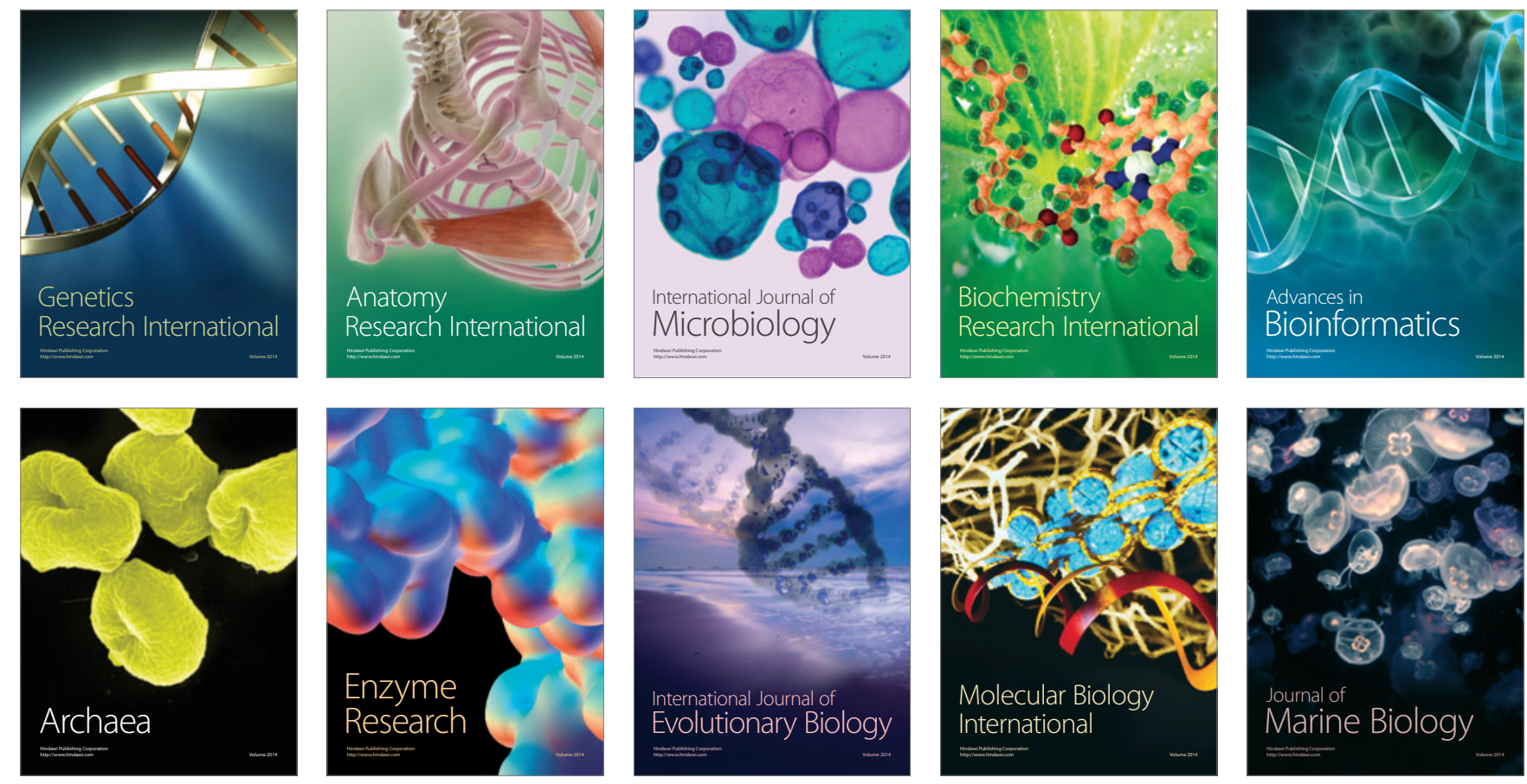